\title{
ISSUES IN TEXT-TO-SPEECH FOR FRENCH
}

\author{
Evelyne Tzoukermann \\ AT\&T Bell Laboratories \\ 600 Mountain Avenue, Murray Hill, N.J. 07974 \\ evelyne@research.att.com
}

\begin{abstract}
This paper reports the progress of the French text-to-speech system being developed at AT\&T Bell Laboratories as part of a larger project for multilingual text-to-speech systems, including languages such as Spanish, Italian, German, Russian, and Chinese. 'These systems, based on diphone and triphone concatenation, follow the gencral framework of the Bell Laboratories English TTS system [?], [?]. This paper provides a description of the approach, the current status of the French text-to-speech project, and some problems particular to French.
\end{abstract}

\section{Introduction}

In this paper, the new French text-to-speech system being developed at AT\& $\Gamma$ is presented; several steps have been already achieved while others are still in progress. First we present a brief description of the phonetic inventory of French, with a discussion of the approach used to select and segment phonetic units for the system. Methods for automatic segmentation, and for the choice of diphone and triphone units are presented. Some comments on durational and prosodic issues follow. We conclude with some discussions on directions for future improvement, including morphological analysis, part-of-speech tagging, and partial phrasal analysis for the purpose of phrasal grouping.

\section{Phonetic Description of French}

The French phonetic system consists of 36 phonemes, including 17 consonants, 16 vowels, and 3 somi-vowels. Table 1 shows the different phonemes; the IPA column contains the phonemes in the standard International Phonetic Nlphabet; the second column Ascu shows the ascii correspondence of these characters for the text-to-speech system, and the third column shows an example of the phoneme in a Erench word.

\begin{tabular}{|c|c|c|c|c|c|}
\hline \multicolumn{3}{|c|}{ Consonants } & \multicolumn{3}{|c|}{ Vowels } \\
\hline IPA & ASCIY & WORD & IPA & Ascry & WORD \\
\hline $\mathrm{p}$ & $\mathrm{p}$ & paix & $\overline{\mathrm{i}}$ & $\mathrm{i}$ & vive \\
\hline$t$ & $\mathrm{t}$ & tout & $\mathrm{e}$ & $e$ & the \\
\hline $\mathrm{k}$ & $k$ & cas & $e$ & $\mathrm{E}$ & aise \\
\hline b & b & bas & a & a & table \\
\hline d & d & dos & $a$ & a & âme \\
\hline $\mathrm{g}$ & $g$ & gai & 0 & $>$ & homme \\
\hline $\mathrm{m}$ & $\mathrm{m}$ & mais & o & 0 & tôt \\
\hline $\mathrm{n}$ & $\mathrm{n}$ & non & u & $U$ & boue \\
\hline $\mathrm{n}$ & $\mathrm{N}$ & gagner & $y$ & $y$ & mur \\
\hline i & 1 & livre & $\phi$ & 11 & eux \\
\hline $\mathrm{f}$ & f & faux & $\infty$ & (a) & seul \\
\hline s & $s$ & si & ə & $\&$ & peser \\
\hline $\int$ & $\mathrm{S}$ & chanter & $\tilde{\varepsilon}$ & I & bain \\
\hline $\mathrm{v}$ & v & vive & $\tilde{a}$ & $\Lambda$ & banc \\
\hline$\%$ & $z$ & zero & $\tilde{3}$ & () & bon \\
\hline 3 & $Z$ & jupe & $\tilde{\infty}$ & I & brun \\
\hline \multirow[t]{6}{*}{$\mathrm{r}$} & $\mathrm{r}$ & rare & 0 & $\wedge$ & samedi \\
\hline & & \multicolumn{3}{|c|}{ Semi-vowels } & \\
\hline & & Ascil & $w$ & R.D & \\
\hline & & $j$ & & $\operatorname{enx}$ & \\
\hline & & $\mathrm{w}$ & & oui & \\
\hline & & W & & uit & \\
\hline
\end{tabular}

Table 1: French Phonetic Phonernes

For the French text-to-speech synthesis system we use 35 phonemes, consisting of 17 consonants, 15 vowels (and not 16 like in the Ir. column), and 3 semi-vowels. As shown in Table 1 , the fourth

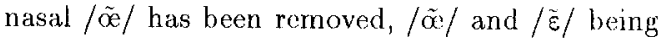
represented by the single phoncme $/ \tilde{\varepsilon} /$. The reasons for this change are that (1)/ $/ \tilde{x} /$ tends to be assimilated to the phoneme $/ \tilde{\varepsilon} /$, and (2) this nasal vowel occurs in very few words in French. Thus, 
it conld be said that functionally the distinction between $/ \tilde{x} /$ and $/ \tilde{\varepsilon} /$ is minimal. trench also comtains two phonemes for the character " $a$ " $/ \mathrm{a} /$ and $/ a /$, the first one being a front untounded vowel and the second one a back rounded vowel, $A$ small number of French speakers make this production and perceptual distinction; in addition, today's tendency shows a disappearance of this phonemic disctinction. Therefore, only /a/, the most com. mon phonene of the lwo, was retained for synthosis. Notice that two different. "schwas" (or mutec), marked as $/ \& /$ and $/ \wedge /$ were retained for synthesis; since schwa in spoken tirench can be, in some cases, present or not depending on the level of formality of language - it is uscful to have two different signs to account for this option. In addition, the grapheme-to-phoneme system used in the Fronch T"TS system and described in Section ??, is oquipped with the capability of including or not the schwa depending on the level of language. lior example, the sentence "jo m'en vais samedi", l am leaving on salurday, can be said either/so mã ve samodi/ or, more colloquially, /smà ve samdi/. depending on whether the schwa is redued or not. In our system, the sentence will be transcribed $/ 3 \wedge$ má ve samm $\wedge d i /, \wedge$ accounting for the trace of the schwa. An additional character "*", was used to repesent silences at the beginning and end of words.

French phonemes can also be viewed accoreling to their spectral variability in the context of other phonemes. It is known that lirench vowels show spectral stability and low contextual variability [?], [?]. The voiceless fricatives show somewhat less spectral stability, then the plosives. The nasals and voiced fricatives prosent oven less stability. Tiquids (/l/ and $/ \mathrm{r} /)$ and semi vowels $(/ \mathrm{j} /$, $/ w /, / 4 /)$ are the phonemes showing high variability and this poses problems in diphone based synthesis [?]. Liquids are very sensitive to their context; formant structures show substantial of fects of conticulation. As for the semi vowels, it is diflicult to capture the zone of spectral stability.

For these reasons, some reseachers, e.g. [?], organize phonemic classification using the criteria of the stable ves unstable phoneme rather than place of articulation. Similar to the approach in the Buglish 'T'IS systern, synthesis for Prench is done using prestored units. Within this framework, there are various strategies for the collection of units, units that will then constitute the? dietionary of polyphones. Due to the continual aspect of the spoech signal and the fact that the uature of phonemes is greatly modified in the context of older phonemes, synthesizing separate phonemes cannot capture articulatiory aspects of the language. Adelitionally, transitions are hardor to model than stcady states. 'Thus, diphones are the standard minimal units in segmental synthesis. From an acoustic standpoint, a diphone can be seen as a signal passing from the central part of a phoneme to the central part of the subsequent phoneme; in other words, it is a unit composed of two half phonemes. At a segmontal level, one cau think of a diphone as a stored length of speech that goes from near the target of one phoneme and extends to near the target of the following one, in other word the transition [?].

'The earliest diphone system was deseribed by Peterson et al [?]; other diphone approaches have been reported by [?], [?], [?], and [?]. Although there are only about, 40 phonemes in English about, 1600 diphones suffice for synthesis. Neverthe less, because of numerous allophones and the fact that some diphones are not really context-free, re scarchers like Peterson suggest that about 8000 diphones are noeded for high quality diphone syn. thesis. Morcover, the vowel diphtongs in Linglish could be treated as peudo-diphones. Larly lronch synthesis systemes [?] relied also on synthesis by diphones except for the diphone [yi] that is integrated in a triphonic gromp. Ithis phonomic pair was stored differently bocause of its high frequency in lrench in occurrences such as "lui" him/her. In more recont work, systems contain diphones and larger units, such as triphones, quadriphones, and cven quintophones [?] [?], in order to capture coarticulatory phenomena of a longer domain that would not be adequately modeled in a strictly diphonic system.

lu the current system, the diphone inventory for firench was built by laking $35^{2}$ phonemic pairs, that is 1225 units. Added to that was the silences symbol in initial and final position, which adds another 70 phonemic pairs. From this initial set, the pairs of semi-vowels were removed. All the other combinations were kept. Lven though all of them do not occur in French lexical structure, they can still appear in the inter-word boundaries. For example, the sequence / $/ \mathrm{r} /$ is not permitted word internally, but must be handled since it, appears in the interword assimilation in / val rje/ "valent, rien" cost nothing. This is particularly important in French since inter-word liaison is common as in /El " כ/ "clles ont" they have vs /el sj/ "elles sont" they ure, whero the final consonant /s/ either undergoes liaison with the vowel $/ \tilde{\partial} /$ resulting in $\mid z /$, or undergoes linking with the consonant $/ \mathrm{s} /$ 
resulting in the devoiced sibilant.

\subsection{Diphone Structure and Selec- tion of Carrier Word}

\subsubsection{Structure of Diphones}

This section discusses the nature of the diphone set and the manner in which diphones were collected. Diphones are structured as follows:

$$
* \mathrm{~V}, * \mathrm{C}, \mathrm{V} *, \mathrm{C} *, \mathrm{CV}, \mathrm{VC}, \mathrm{CC}, \mathrm{VV}
$$

where ${ }^{*}$ is a silence, $\mathrm{C}$ a consonant, and $\mathrm{V}$ a vowel. Semi-vowels were treated in the same fashion as consonants. Diphones were recorded following two different strategies: the first one consisted of picking existing words from a dictionary list. 'The second consisted of deciding on a neutral phonetic context in using logatomes or nonexisting words. Logatomes are phonotactjically well-formed strings, which do not exist as words in the current Fronch language.

\subsubsection{Selection of existing words from machine-readable dictionary}

A word list was extracted from a subset of the Robert French dictionary [?] and the pronunciation fields were extracted. The dictionary contains almost 89,000 entries, of which 85,796 entrics contain a headword, a phonemic transcription, and a part of speech. The remaining entries are prefixes and suffixes. The first task consisted of converting and mapping the dictionary phonemic symbols to the ones adopted in our system (shown in table 1). 'This was not straightforward since there was not always a onc-to-one mapping between the two sets. For handling symbol mapping, a program was written that converts any set of characters to any other set of characters ${ }^{1}$. The program is developed so that characters coded in octal or decimal code not only can be translated in either code, but also can be input in ascii format for being converted ${ }^{2}$.

Quite often, there was more than one pronunciation in the phonctic field and the pattern matching program chose the pronunciation corresponding to the one required. Moreover, dictionary pro-

\footnotetext{
${ }^{1}$ I am very grateful to Mike Canenblatt who wrote this program and made a succession of changes until complete flexibility of character conversion was obtained.

${ }^{2}$ This tool allowed the conversion of databases originally written on Macintosh, PC, or Unix. Additionally, we used it to convert all the French lextual databases into latin1 8 bit encoding format.
}

nounciation fields are often not phonctically fincgrained enough for acceptable speech output (see [?] for a discussion on machine-readable dictionarics in text-to-speech systems). Finally, due to the lack of explicit inflectional information for nouns and adjoctives, only the non-inftected forms of the entries were extracted during dictionary lookup. Similarly for verbs, only the infinitival forms were used since the dictionary does not list, the inflected forms as headwords. A program was written to search through the dictionary pronunciation ficld and select the longest word where the phoneme pairs would be in mid-syllable position in order to avoid the extraction of phonemes occuring at the beginning or end of words. In this way, the influence of lexical stress was reduced. The orthography/pronunciation pair [headword_orth, headword_phon] was extracted and headword_orth was placed in a carricr sentence for recording. Out of 1225 original phonemic pairs, 874 words wero found with at least one occurence of the pair. Because 1225 is the number of all phonemic pairs in French whether they are allowed or not, it is interesting to notice that only 874 pairs occur within real words in the Robert dictionary.

\subsubsection{Selection of logatomes}

For the logatomes, two phonemes /a/ and/t/ were used to encompass the selected diphone, since they appear to be fairly stable from a phonetic-aconstic standpoint. In order to balance the alternation of vowel and consonant, the words were constructed as follows:

\begin{tabular}{||l|c|r||}
\hline Logatome position & Structure & Example \\
\hline initial vow. & ${ }^{*}$-ta & ota \\
initial cons. & ${ }^{-C-a t a}$ & bata \\
final vow. & at- ${ }^{*}$ & ato \\
final cons. & ta-C* & tab \\
cons. vow. & ata-CV-ta & atabota \\
vowel cons. & at-VC-ata & atibata \\
cons. 1 cons. 2 & ata-CC-ata & atakrata \\
vow 1 vow 2 & at-VV-ta & atoata \\
\hline
\end{tabular}

Table 2: Phonotactic structure of logatomes

All strings were generated in this way, evon if they were not phonotactically well-formed for isolated words in the language. Nonctheless, these forms were generated and used since they were necessary for interword phenomena. Approximatoly 1225 words were constructed following the above model. 
Rescarchers disagree as to whether to use logatomes or real words for synthesis. 'The argument for asing logatomes is that it is better to collect non-real words so that the diphome is recorded as neutrally as possible and does not $1 \mathrm{~m}$. dergo any real word stress. 'T'hose against argue that the diphone is over-articulated in a logatome environment and that it reduces the naturaluess of the syuthesized speech. The choice is more complex in the sense that it greatly depends on the speaker, the articulation, and the comfort in reading the two different sets. Given the controversy, in the present system, we decided to record the phonemic pairs in both environments, so that we could choose the best ones.

\subsection{The other polyphonic units}

Due to the variability of liquids and semi-vowels, synthesis based only on diphones will not give good results. Indeed, such systems have proven to be insufficiont. Researchers [?] argue that diphone concatenation alone is not adequate or sufficient, particularly for complex transitions. [?] claims that "ideal diphones with perfect concatenation would give imperfect results". Complex polyphones are not equivalent to concatenated diphones. Therefore, longer concatenative units are necessary. Polyphones are defined by [?] as being a segmental unit where the initial and final phoneme are not subject to variability, thus, excluding liquids and semi-vowels.

The strategy chosen in the l'rench system relies on some phonetic generalities to build a set of triphones. It was decided ${ }^{3}$ to form a class of triphones, based on the following transition: PVC, where $P$ ' is a phonemo, $V$ a vowel, and $C_{c}$ a consonant representalive of the articulatory locations, i.e. one velar, one dental, and one nasal. The set consisted then of 35 phones $x 14$ vowels $x 3$ consonants $=1470$ triphones. 'The same methodology used for building the set of diphones was used for the triphones. 'These were inchuled in a carrier word for the logatomes and extracted from the dictionary for the real words.

Researchers disagree on which criteria are best for the selection of triphones; should the selection rely on phonectic-acoustic ovidence, or on statistical evidence related to the frequency of occurrence of triphones in the language? 'Jhen, once the criteria is defined, which triphones should be selected? Car candidates of a class (say the phonome $/ \mathrm{p}$ /

\footnotetext{
"personal communication with Joe Olive
}

representing all the stops, the phoneme/v/ represeuting all the fricatives) be picked to represent a class or should all the phonemes belonging to the class be selected? Research is underway in this arca using a phoneme clustering approach [?], [?] that allows the selection of segmental units from a database of phonemes containing several instancess of the same phoneme. The extraction is made at a spectral point common to the phonemes. Fi nally, because the number of selected units affects results, the choice of polyphones must be made with care. laking into account the size limita tion, one has to balance out the choice of the polyphones considering its frequency in the language. This brings in the additional complexity of corpus selection (its language properties, dialects, sociolinguistic type of language, topic, and size).

[?] applies a series of rules on phoneme contbination to exclude inter-word concatenation that would not occur in Prench. For exarnple, one cannot find a glide in firench that is not in the loft or right context of a vowel; therefore, the combination consonant-glide-consonant is excluded. An optimal set of polyphone combinations is computed that reaches a mumber of 7725 units. Calenlated from texts, statistics are then run on these units to determine the most frequent occurences in lirench, and the number of units is lowered to 3000 . It remains to be seen whether this approach is successfull in a working system.

\subsection{Construction of the corpus}

A carricr sentence "C'est carrier.worm que je dis" was selected to fulfill the following requirements:

- short sentence to record,

- ability to surround the carrier word to avoid sentential accent and effects,

- phonetically neutral environment.

\subsection{Choice of a Speaker}

Five male native speakers of Continental French were intervicwed for solecting the voice of the French synthesizer. A sample of text representing highly occuring graphemic trigrams was prepared to be used in this task. 'The corpus was run through a groedy algorithm ${ }^{4}$ that returned the most frequent words within their sentences

\footnotetext{
4'Thanks to Jan Van Santen for developing and runing his greedy algorithm.
} 
along with a measure corresponding to the covcrage of the graphemic triphone. Once the sample was recorded by the 5 speakers, the natural voices were run through LPC analysis and re-synthesized in order to judge the resistance of the voice to synthesis. Five subjects were asked to give their judgement on the following criteria:

1. clear articulation: the voice was carefully listened to evaluate the articulation of the speaker. Subjective perceptual judgements were made.

2. neutral French accent: the candidate was asked about the areas of france where ho grew up. 'The central area of France "l'Ile do France" is known for its neutral accent and is regarded as being a well-received accent. Additionally, for French native spcakers residing in the USA, particnlar attention was paid to the infuence of English in the pronunciation of French, especially for English borrowings, such as for example, the company name $\Lambda T \& \mathrm{~T}$ to be pronounced / a te te/ (the French way) and not /ei $t n t /$ as in English.

3. regularity: special attention was given to ensure that the speaker would have a reasonable degree of regularity in uttering French phonemes.

4. pleasantness of the voice: the subjects doing the evaluation were asked to give their opinion on the pleasantness of the voice, in particular the timber, the level of nasality, and the intonation. Of course, this is a highly subjective matter but a critical one for success.

\subsection{Recording Conditions}

The recording was done on four non-consecutive days under the following conditions. The sentences were recorded directly onto the computer through a DAT (Digital audio Tape) tape recorder, using interactive software allowing easy reading and repctition of the sentences to be recorded. Additional time was devoted to the recording of triphones as well as the re-recording of sentences that were improperly uttered. 'I'he same carrier sentence and a regular prosodic context was carefully maintained so that there was minimal suprasegmental variation. Once the recording was done, the $48 \mathrm{kHz}$ digitized acoustic signal was downsized to $12 \mathrm{kHz}$.

\subsection{Transcription of recording ma- terial}

For the recording, all sentences were transcribed from the phonetic alphabet to an orthographic format. This was done to allow the speaker to utiter sentences with more naturalness. Once the recording was done, the sentences were semiautomatically re-transcribed into phonetic form. For some utterances, the phonetic transcription was manually adjusted to the idiosyncrasies of the speaker. For example, it often happened that confusion arises between open and closed vowels, such in the word "zoologique" zoological that can be pronounced either /zoolozik/ or / zoslogik/. In case the output was /zoolozik/ instead of the expected /roolozik/, the transcription was readjusted.

\subsection{Segmentation}

Segmentation is presently in progress; efforts are being pursued to adapt an automatic segmentor for English to French and other languages. In tho meantime, manual segmentation is being done as a pilot experiment in order to check the accuracy of automatic segmentation. Beyond the scope of this paper are many complex issues raised in segmenting lirench, such as the segmentation of semivowels $(/ \mathrm{j} /, / \mathrm{w} /$, and $/ \mathrm{l} /)$ and liquids $(/ \mathrm{l} /$ and $/ \mathrm{r} /$ ). each of these phonemes being quite unstable from a phonetic-acoustic standpoint. 'These issues will be addressed in future work.

\subsection{Integration of an orthographic transcriber}

A grapheme-to-phoneme transcriber [?] was acquired to convert lirench orthography to a phonemic representation. The software performs some syntactic and partial semantic analysis of the sentence in order to disambiguate the input string. Once performed spellings are converted in a series of steps into a phonemic representation.

\section{Issues in Text Analysis}

We have pursued work in the text analysis of French in order to obtain linguistic data for intonation and prosody; additionally, the output of the work will be used in the translation project. This aspect of the work has entailed several points:

- acquisition of a large French dictionary: Robert Encyclopedic dictionary (containing 
over $85 \mathrm{k}$ entries, $80 \mathrm{k}$ articles, $160 \mathrm{k}$ (ilations, analogical terms (symonyms, homonyms, etc), and conjugation tables for most french verbs).

- collection of French corpora:

French news from $J_{j}$ lis MONDE [?]

French news daily compiled by the French cmbassy in Washington DC (24657 K bytes are now encoded, and a monthly uprlate is being done). The data are in ascii and accents were restored using one of the features of tho graphenc-lo-phonene softwares. Another program was wriliten to antomatically clean and normalize these email Commat data

extraction of some of the Robert dictionary databases: the 160,000 citations from literary French aubliors are being extracted so that they can constitule some relevant corpus datia. A franowork is being worked out so that citalion anthor can be retriced on an optional basis.

- cncoding of French data using the already existing scheme developed by [?] and entanced by [?]. 'This scheme allows the use of the concordance progrant. As English data are encoded in 7 bit characters, an 8 bit encoding format was worked out to allow the retrieval of French toxt with accents ". For example, the maceented word "cote" in french can be several words: "cote" with no accent meaning quotation, rating, "cote" moaning coast, and "coté" meaning side all these translations being also valid in the figurative sense. 'Jhus, a latinl compatible window would display lrench corpora with accents; in the following example, the program returns all intances of the word "cote" (quotation, rating) in the database "Ie Monde". The query to the system will reticeve all the lirench sentences where the exact mateh to the characters "cote" will occur, and ucither of the other spelling:

The query producing table?? returned information of "Le Monde" only, as requested. In specifying "FRLN" for l'rench, the following query in 'lable ?? returns all instances of

\footnotetext{
"I am very geateful to IJavid Yarowsky for encoding the? E'rench datia.
}

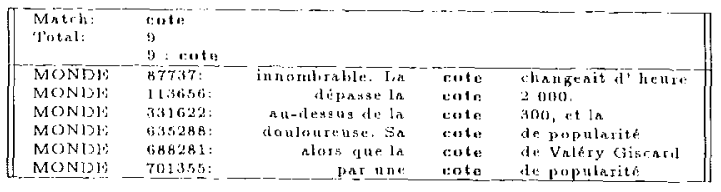

Table 3: Some concordances of the word "cote" in the datiabase "Lo Monde"

the word "cote" in the three Prench corpora. Moreover, the "i" option allows the retricval of all instances of a word with or without ac. cent, therefore the three French words "cote", "cote", and "cote". For more information on the use of the concordance tools, refer to [?].

\begin{tabular}{|c|c|c|c|c|}
\hline $\begin{array}{l}\text { Match: } \\
\text { 'lotal: }\end{array}$ & $\begin{array}{l}\operatorname{cost} \theta \\
0 \\
9: \operatorname{cost} t\end{array}$ & & & \\
\hline$M(\overline{O N}) \mathrm{B}$ & $205 \overline{1}:$ & itall Hench, surla & inte & diententin \\
\hline MONDI: & 2 2nrt: & $\begin{array}{c}\text { pied sur la } \\
\text { pind }\end{array}$ & côte. & (gii' its geraicul \\
\hline MONIDL: & $3835:$ & prévia: la & oats: & du Calvados. \\
\hline MONIDIS & 41)81: & de cenx ife la & :óte & sut de \\
\hline MONIMI: & A150103: & univeraites di la & cinte & atlantiqur. \\
\hline $\mathrm{APP}$ & 25701 & savent. & coté & Iravailliste \\
\hline $\mathrm{Air}^{3}$ & 433546: & plath Shamis. & Côte & isrulien \\
\hline Alp & 53871 & :n-Auxnis, $\in \mathrm{n}$ & cote & d'Or. \\
\hline 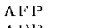 & 126794 & Ganermul, & conte & A' luokn, \\
\hline Al: & $181788:$ & sécurité". & conte & libanais \\
\hline$A E^{2}$ & 188101: & xut: & cots & franciais \\
\hline HANSE: & $267386 \mathrm{t}$ & is mettre de & $\Leftrightarrow o t e$ & l' antipathit: \\
\hline IIANBE & 271232 & thet tivnsible du & cots & des ministériels. \\
\hline IIANSL" & 272137 & del' autre & 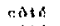 & $d: \operatorname{lar} r$ ra: \\
\hline IIANGE & $2755000:$ & de l' nuter & cots & de la chaulut \\
\hline $11 A N S V^{\circ}$ & $-276522:$ & arriextobans du & conts & dugouvermestent \\
\hline
\end{tabular}

Table 4: Some concordances of the word "cote" in all French daliabases

- development of a morphological analyzer and generator for French, using finite-state transducer: the system is built with an approach similar to the one for Spanish [?]; it, is mainly based on the headwords of the Robert dictionary.

- accent filters: conversion tables are still being produced al each time a new database arrives that is not in a compatible form.

\section{Conclusion}

'The French 'I"LS system is part of a large project of multilingual text-to-speech synthesis in progress at $\Lambda^{\prime} L^{\prime}{ }^{\prime}$ ' Bell Laboratorics. Speech synthesis for lirench brings a variety of challenges, some of which are specific to l'rench, such as nasalization, liaison, schwa realization, etc. and some of which are more general issues, such as vowel lengthening, prosodic contouring, and intonation. Several systems are in experimental stages for other languages, such as Spanish (Castillan as well as South American), Italian, Chinese, Navajo, Gernan, and Russian. Once Continental French is completed, 
we also intend to build a TTS system for Canadian French.

\section{References}

[1] Veronique Aubergé. La synthèse de la parole: 'des règles aux lexique'. PhD thesis, Université de Grenoble, Grenoble, France, 1991.

[2] Jared Bernstein. Speech synthesis: System design and applications. pages $3942 . \mathrm{Na}-$ tional Computer Conference, 1987.

[3] Frédéric Bimbot. Synthèse de la Parole: Des Segments aux règles, avec utilisation de la décomposition temporelle. $\mathrm{PhD}$ thesis, 'Telecom Paris 88 E019, Paris, France, 1988.

[4] M. Chafcouloff. Les propriétés acoustiques de $[j, y, 1, r]$ en fran cais. volume 6 , pages 10-24. Travaux de l'Institut de Phonétique d'Aix, 1979.

[5] N.R. Dixon and H. D. Maxey. Terminal ana$\log$ synthesis of continuous speech using the diphone method of segment assembly. In IFEE Transactions on Audio and Electroacoustics AU16, pages 40-50, 1968.

[6] Francoise Emerard. Synthèse par diphones et traitement de la prosodie. $\mathrm{PhD}$ thesis, Université de Grenoble [II, Grenoble, France, 1977.

[7] Alain Duval et al. Robert Encyclopedic Dictionary (CD-ROM). Hachette, Paris, 1992.

[8] Judith Klavans and Evelyne Tzoukermann. The use of machine-readable dictionaries in text to speech, under review, 1994.

[9] P. Laferrière, G. Chollet, I. Miclet, and J.P. Tubach. Segmentation d'une base de donnces de 'polyson', application à la synthèso do parolc. In JEP: 14, pages 107--110, 1985.

[10] L'histoire au jour le jour 1944-1991. In version 1992. CD-ROM, 1992.

[11] F. Marty. 'Trois systèmes informatiques de transcription phonétique et graphémique. Le Fran cais Moderne, LX, 2:179-197, 1992.

[12] L. Miclet. Enregistrement d'une base de données vocales. In $L A A / T S S / R C P$ H.N.S.T. CNEI, 1984.
[13] Joe P. Olive. Rule synthesis of speech from dyadic units. In Procedings of the ILEFICASSP, pages 569-570, 1977.

[14] Joe P. Olive. A new algorithm for a concalenative speech synthesis system using an augmented acoustic inventory of spech sounds. In Gerard Bailly and Christian Benoit, editors, Proceedings of the ESCA Workshop on Speech Synthesis, 1990.

[15] Joe P. Olive and Mark Y. Liberman. $\Lambda$ set of concatenative units for speech synthesis. In In J. J. Wolf and D. H. Klatt, editors, Speech Communication Papers Presented at the $97 \mathrm{th}$ Meeting of the Acoustical Socicty of America, pages 515 518, New York: American Institutite of Physics, 1979.

[16] G. E. Peterson, W.S.Y. Wang, and E. Siversten. Segmentations techniques in speech synthesis. Journal of the Acoustical Society of America, 30:8:739-749, 1958

[17] Scott Rosenberg and Joseph P. Olive. Expediting the selection and clipping of multiphone sequences for acoustic inventory. In 11220-930890-12TM, Murray Hill, N.J., USA, 1993. Technical Memorandum, A'I\& Bell Laboratories.

[18] Jim Rowley. Phonemo clustering tools. In 11220931123-25TM, Murray Hill, N.J., USA, 1993. Technical Memorandum, LT\& Bell Laboratories.

[19] R. Schwartz, J. Klovstad, J. Makhoul, D. Klatt, and V. Zue, Diphone synthesis for phonetic vocoding. In Proceedings of the ILEE-ICASSP, page 891, 1979.

[20] Evelyne T'zoukermann and Mark Y. Liberman. A finite-state morphological processor for spanish. In Proceedings of Coling90, Helsinki, Finland, 1990. International Conference on Computational Linguistics

[21] Church Kenneth W. Concordances for parallel text. Oxford, England, 1991. Seventh Annual Conference of the UW Centre for the New OED and 'lext Research.

[22] David Yarowsky. Conc: 'Tools for text corpora. In 11220-921202-29TM, Murray Hill, N.J., USA, 1992. Technical Memorandurn, AT\& Bell Laboratories. 